conserve (migratory) shorebirds in the Yellow Sea region. At least the classical concepts might not work well, and RAMSAR agreements and other full-blown international political tool boxes are weak and soft; e.g., due to lack of enforcements and binding. Of interest is the progressive coastal ecoregion approach presented in Chapter 7, which allows one to characterise shorebird habitat with a variety of multidisciplinary habitat data. Much more of such work is needed in order to provide quantified results for shorebirds as well as their habitat.

Although major countries like China, North and South Korea are currently not well known for their efforts to conserve shorebirds and their habitat, this

\section{Birds of the World: A Checklist}

By James F. Clements. 2000. Ibis Publishing Company, Vista, California. 867 pp.

Let's be clear about one thing, this is not a field checklist. It's a massive, door-stopping tome. But what a tome it is: all serious birders and ornithologists will want to own their own copy of this long-awaited and authoritative work. For over a decade successive editions of "Clements" have been the authority when it comes to questions on what counts, and what doesn't: the American Birding Association has long used it as its global listing standard. The latest edition will not disappoint.

The bulk of the book consists of a comprehensive listing of all the species of birds of the world. Species names and taxonomy largely follow decisions of the American Ornithologists Union and the British Ornithologists Union; where the author varies from this appropriate references are provided. Each entry has the English name of the species in bold print, followed by the Latin name in italics. In a major improvement over earlier editions, this is followed by a listing of all acknowledged subspecies, albeit in Latin only. This is an exceedingly useful feature, particularly given the pace of taxonomic change in which today's subspecies could be tomorrow's species. Beside each subspecies entry is a short description of its global range. Each species has a handy tick box for those hard-core listers out there and a space to enter information on your own sightings. That's it; no text, no photos, no maps.

There is a short introduction, a helpful list of abbreviations ("Tas." stands for Tasmania), another helpful list of orders and families, and a shamefully long list of extinct species (almost all from islands). There is also a list of major family references for those who want to get into the details or argue about specific decisions, as well as an extensive bibliography. A gazetteer provides geographic reference points for places cited in the text. Listers - and biogeographers - will find the lists of endemic bird species by country, and the dis- publication will hopefully help to improve the current situation and force the governments eventually to take (coastal) environment issues seriously. The author can be congratulated for his tremendous effort providing the international community with such a splendid report on shorebird conservation and crucial baseline data.

\section{FAlK HuetTManN}

Department of Geography-Earth Science, Calgary University, 2500 University Drive N.W., Calgary, Alberta T2N 1N4 Canada Present address: Biology and Wildlife Department, Institute of Arctic Biology, University of Alaska, Fairbanks, Alaska 99775-700 USA tribution of bird species by country, highly useful. Rounding out the picture are separate indices of scientific and English names. The front piece has a colourful map showing the distribution of bird species by country, the end piece a similar map showing endemic species, also by country.

The approach taken by Clements is unflinchingly anchored in the biological species concept; a species is considered valid when it is reproductively isolated. This is in contrast to a phylogenic approach which looks for clusters of shared characteristics. This may disappoint some, as is the decision to not recognize as discrete species many insular forms. Nonetheless, the number of recognized species has exploded from 8600 to 9700 , largely based on increased knowledge, including the growing use of DNA analysis. Few global travellers will fail to see their bird list grow by a careful analysis of the revised listing, and many Canadian subspecies have been elevated to full species.

One of the most exciting aspects of this work is its evergreen character; inevitably a book of this nature is out of date almost as soon as it is published. To counter this the author has made it a living work by periodically posting updates to the publisher's web page: serious birders will add "www.ibispub.com" to their internet bookmarks and visit regularly to keep track of the latest lumps and splits. At the time this review was written there have been several updates. For example, in December, 2002, American Herring Gull, Larus smithsonianus, was elevated to full species level. Not surprisingly, there is also a software companion (at an extra cost) to help you keep track of sightings electronically, and the "Clements" list is already the standard in competing software out there.

Are there flaws? It would be impossible for a few not to creep in, and a careful perusal will quickly turn up several, starting on page one, where the line to enter your comments is missing for Northern Cassowary. Also, and despite being a great birding destination, Jamaica has "only" 27 endemics, not the 200-300 one 
might assume from the end piece. Bird rich Bolivia somehow was left out of both the country summaries. Range descriptions are inconsistent, for example, for Laysan Albatross we learn that it breeds on various islands but also that it "ranges n Pacific", whereas for Black-footed Albatross we learn only where it breeds. Similarly, Lesser Black-backed Gull, surely a fixture of the North American avifauna, is noted only for the old world. Introductions go unnoted, thus there is no indication that House Sparrow occurs in North America. While the list of extinct species is already long enough, it is perhaps optimistic to omit from it Sunda Lapwing, unrecorded from heavily populated and wellwatched Java for over eighty years. On a somewhat related note, the decision to drop the symbol in earlier editions indicating that a species is "red listed" by the World Conservation Union/IUCN was unfortunate.
These flaws are largely inconsequential; however, there are also errors in the taxonomy. Many of these are being picked up in the periodic updates and the web page encourages readers to report any errors that they find. One egregious Canadian example is the Sharptailed Sparrow complex where subvirgatus and alterus are listed as Saltmarsh Sharp-tailed Sparrow caudacutus, as opposed to Nelson's, nelsoni, neatly adding James Bay to the former species' breeding range. Despite these flaws, if you are a serious ornithologist, an avid global birder, or need a one-stop reference which lists every species and subspecies of bird on the planet, this book is for you.

MARK GAWN

1354 Viking Drive, Ottawa, Ontario, K1V 7J6 Canada

\section{The Rockfishes of the Northeast Pacific}

By Milton S. Love, Mary Yoklavich, and Lyman Thorsteinson with contributions from John Butler. 2002. University of California Press, Berkeley. $\mathrm{x}+405$ pp. Cloth U.S.\$92.95, paper U.S.\$26.95.

There are a least 65 species of rockfishes (family Sebastidae) in the northeast Pacific Ocean from Mexico to Alaska including about 38 from British Columbia (my count from maps in this book and other sources, the book lists 30-35 species and its maps 31-35). It describes 2 species not given in Hart (1973) nor in Coad et al. (1995) for Canada, namely Sebastes melanostomus and S. rufus. Rockfishes are important and sometimes dominant components of the marine ecosystem, may live as long as 205 years, have been sought for food and sport, and populations are in severe decline.

The book comprises a series of introductory chapters covering the biology of rockfishes, their evolution, their names, and their fisheries. The biology sections cover habitats, reproduction, ecology of pelagic young, juvenile settlement, movements and activity patterns, age and growth, parasites, abnormalities and diseases, fisheries, and conservation. These are followed by a key to species, species accounts (169 pages), references (34 pages), locality maps, 8 appendices, a glossary, an index, and lists of reviewers, personal contributors, contributing authors, photographers, and artists.

The species accounts comprise scientific name, official common names (as recommended by the American Fisheries Society Committee on Names of Fishes), etymology, colloquial names, a distribution map, description of the fish as it appears underwater and after capture, particularly important for deepwater species that appear very different once hauled to the surface, maximum size, range both geographic and depth, life history, fishery, remarks, and references. Remarks include taxonomic comments but also life history data are not included in that section, which seems an unnecessary separation of information.

The book has a number of strengths. There is an extensive list of references, several underwater colour photographs of most species that effectively convey the variation in these colourful fishes, comments in the species descriptions of similar species and how to differentiate them, and appendices listing such items as parasites, growth and length-weight curves, meristic characters, and the infamous head spines through which these species are often identified. Some art work is unnecessary (see below) but the gyotakus (fish prints from fresh specimens) are very beautiful and add to the argument that "rockfishes are cool".

One criticism is that the drawing of head spine configurations is the same drawing for each species the absence of a line from a label name to a spine indicates that spine is absent. This is not intuitively easy to follow or visualize on a fish specimen at hand. Another point needing improvement is the distribution maps. These show the species range as a yellow band along the Pacific coast. The text must be read to find any limitations on this simplistic mapping. Spot distribution maps would better indicate the scientific knowledge, backed by museum specimens, on distribution.

The keys have not been tested by me but as a museum scientist it would fall apart for me at couplet 4 where colour alone is used to separate two lines of identification (and the key goes on for 70 couplets, quite long and therefore easy to lose your way). The authors do admit that the key works best on newly caught fish, may not work with juveniles and will prove frustrating on preserved fish. Some effort could have been made to assuage the museum scientist, perhaps 